\title{
Out-of-school girls in India: a study of socioeconomic-spatial disparities
}

\author{
Susmita Mitra $\cdot$ Sudipta Kumar Mishra $\cdot$ Rajesh Kumar Abhay
}

Accepted: 2 January 2022/Published online: 4 March 2022

(C) The Author(s), under exclusive licence to Springer Nature B.V. 2022

\begin{abstract}
Despite numerous established benefits of girls' education, globally large numbers of girls are out-of-school (OOS). This poses challenges to achieving quality education (SDG 4) and gender equality (SDG 5) by 2030. In India, there are socioeconomic and spatial disparities also. The latest National Sample Survey (2017-18) data provides an opportunity to explore these issues. We used the unit-level data of 117,115 children (5-17 years). Our multivariate logistic regression analysis shows that the likelihood of OOS girls is at least $16 \%$ higher than that of boys. The probability declines at every stage of income quintile from 'poorest' to the 'richest'. The likelihood in urban areas is almost $35 \%$ lower than the rural areas. Compared to the upper castes the probability is higher for the backward castes. Compared to Hindus, the likelihood is higher among Muslims but lower among Christian and Sikh children. Our three-layer crosstabulation reveals that poor Scheduled-Tribes girls are
\end{abstract}

S. Mitra $(\bowtie)$

Council for Social Development, New Delhi, India

e-mail: susmita.mitra81@gmail.com

S. K. Mishra

Department of Civil Engineering, GD Goenka University, Gurgaon, India

e-mail: sudipta.mishra@gdgoenka.ac.in

R. K. Abhay

Department of Geography, Dyal Singh College,

University of Delhi, New Delhi, India

e-mail: rkabhay@dsc.du.ac.in the most vulnerable. The spatial plotting shows that the majority of the vulnerable regions belong to a few states viz. Rajasthan, Uttar Pradesh, Madhya Pradesh, Chhattisgarh, and Gujarat. Therefore, we argue for localized solutions for girls of diverse socioeconomic backgrounds in different regions. The relevance of this study also arises from the fact that there might be a further increase in the number of OOS girls due to the COVID-19 pandemic. ANOVA test suggests that there might be a shift of girls from private to government schools also, which calls for strengthening the public education system to prevent the problem from aggravating further.

Keywords Out-of-school-girls · India · Vulnerableregions · Vulnerable-sections · Education-expenditure

\section{Introduction}

Education has both the intrinsic value of being an end in itself and the instrumental value of achieving other desired goals in life. Moreover, girls' education has wider social benefits. Girls' education has its impacts beyond the girl herself, as the entire community and the country also get benefitted. Girls' education contributes to economic growth through an increase in productivity (Abu-Ghaida \& Klassan, 2004; Birdsall et al., 1993), reduction in the wage gap, and increase in the tax base (Schultz, 2002). It also leads to 
several social benefits such as a reduction in the incidence of child marriage and infant and maternal mortality (Hill \& King, 1995; Jensen, 2012), declines in population growth by having fewer children and using smart reproductive health practices (Sperling \& Winthrop, 2016; Kim, 2016). Moreover, educated girls are more likely to participate in politics and make concrete changes in the community compared to uneducated girls (Bertini \& Ceretti, 2020). That is why investment in girls' education is considered to be one of the best investments a country can make to break the cycle of intergenerational poverty (Summers, 1992). However, despite various benefits of girls' education, there exist lower educational opportunities for girls in different parts of the world, and a large number of girls remain out of school (OOS).

Globally, for the school year ending in 2018, about 258 million children and youth are OOS, which represents one-sixth of the global population of the school-going age group (UIS, 2019). According to the report, worldwide there is a mild decline in gender parity in terms of OOS rates, but, inequalities persist at regional and country levels. Most of the OOS girls are located in Sub-Saharan Africa, followed by Southern Asia. Within South Asia, because of its country size, India is the home for the largest share of OOS girls (UNICEF, 2014). India has traveled a long journey of inclusive educational development in the last 75 years since independence. Still, this issue poses a serious challenge to achieve Sustainable Development Goal (SDG) 4 to "ensure inclusive and equitable quality education and promote lifelong opportunities for all" as well as SDG 5 to "achieve gender equality and empower all women and girls" by 2030 .

There are both household-level or demand-side factors like poverty, parental education, gender disparity, social exclusion, disability, conflict, displacement or other emergencies, etc. and supply-side factors like distant location of schools, lack of qualified teachers, drinking water, latrines, and other facilities or a different language of teaching than spoken at home, etc. contributing to high numbers of OOS children (Sarkar, 2018). Children not attending school are generally unaccounted in school records, and therefore become 'invisible' and often not considered in policy and decision-making (UNICEF, 2014). According to the report, the lack of data and information on these most excluded children make it even more difficult to reach them. According to
UNICEF (2014) in South Asia, these children are mostly with disabilities, doing child labor, from poor families of rural areas or urban slums, living in emergency settings, and mostly girls.

Various reasons have been cited in the existing literature for gender discrimination in education and why girls remain OOS in the world as well as in India. Girls face pro-male bias within-household allocation of educational expenditure through two channels: a) enrolling sons and not daughters in the secondary school age group, and b) sending sons to private schools and daughters to the fee-free government schools (Azam \& Kingdon, 2013). Gender discrimination in different forms e.g. access to learning resources, access to free time to devote to learning activities, and cultural attitudes, get translated into gender inequality in learning outcomes (White et al., 2016). All these get translated into more number of OOS girls compared to boys. Gender discrimination is further interlinked with household characteristics like caste (Kelly et al., 2016), educational background of parents, household wealth, and opinions (Kingdon, 2002; Mohanty \& Rammohan, 2015; Sahoo, 2017). Moreover, Lancaster et al. (2008) found pro-male gender bias concerning educational expenditure to be stronger in the more economically backward regions of India.

In this background, the objectives of this study are to explore the recent situation of the extent of the gender gap in terms of OOS children in India, identify the most vulnerable girls, and where are they located spatially? The latest National Sample Survey (NSS) (2017-18) data provides an opportunity to explore these issues. The precise research questions of this study are the following:

1. To what extent gender and other socioeconomic backgrounds are significant determinants of OOS children in India?

2. Who are the most vulnerable girls across different socioeconomic classes?

3. Where are the vulnerable regions in terms of the high probability of OOS girls located spatially?

The findings of this paper offer insights into relevant interventions to ensure SDG 4 and SDG 5 even with limited resources. The findings provide a direction to the Indian Government to prioritize particular socioeconomic classes in specific regions. 
However, a major limitation of the study is that, soon after the latest NSS data got publicly available, the COVID-19 pandemic hit the world including India. Within the short time taken to complete the analysis, various reports started coming in regarding the negative impacts of temporary school closure and online mode of teaching, on girls' education. Therefore, although our results are based on the latest secondary data of the largest pan India level sample, they represent the gross underestimated status of OOS girls in the face of the ongoing crisis. Therefore, we briefly discuss our results in the context of the ongoing COVID-19 pandemic and its future implications.

The remainder paper has been organized in the following sections: Sect. "Conceptual framework" presents the conceptual framework. Section "Data and methodology" explains the data and methodology. Section "Results and findings" provides the results and findings. "Discussions" section links the findings and discusses how the situation might get aggravated due to the present crisis, whereas Sect. "Conclusions and recommendations" concludes with precise recommendations.

\section{Conceptual framework}

Globally, there is no clear definition of OOS children. The term loosely includes the children who either do not have access to a school in their community; or do not enroll despite the availability of a school; enroll but do not attend school, or drop out of the education system. As a part of UNICEF's global initiative on OOS children, profiles of children, who are presently attending school but at the greatest risk of dropping out, have also been taken into account. This is because for the slightest reason if they are pushed out from the education system, they are likely to become the OOS children of tomorrow. If these at-risk children can be identified and prevent them from dropping out, the scale of exclusion might diminish over time (UNICEF, 2014).

In India, the figures for OOS children put out by different official sources show significant variations. As per the survey of the Ministry of Human Resource Development (MHRD), there were around 6.64 million OOS children in the age group of 6-13 years in 2014 (SRI-IMRB Report, 2014). Based on the 71st round (2014) of the NSS data, Pankaj and Mitra (2019) found that there were 15.52 million OOS children in the age group of 6-14 years. According to Bhatty et al. (2017), a major reason behind this was the wide variation in the question posed. For instance, the question asked by NSS was "how many children are not currently attending school," whereas, the MHRD (SRI-IMRB) survey asked, "how many children are not enrolled in any school". Unfortunately, in India, there is a huge discrepancy in being enrolled and attending school.

Conceptually, there are various reasons behind the socioeconomic and spatial disparities of OOS children in a large country like India. Often these factors inflate existing gender inequality in education. Gender discrimination in education has remained for more than thousands of years in India, although the recent forces of modernization and globalization have curbed it to a limited extent (Munshi \& Rosenweig, 2006). The deep-rooted norm in Indian society is not to expect support from daughters (particularly the married ones), which results in less investment in the education of girls (Kaul, 2018). Bhatkal (2012) found gender bias to increase with age, in the entire school-going age bracket. Regarding secondary education, Marphatia et al. (2019) argued that although it is particularly relevant for shaping sex differences in life trajectories, unfortunately, it is often traded off with a good marriage match for girls in India. The gendered division of labor within households often forces girls to take on household duties and care of younger siblings, which often keep them out of school (Kingdon, 2002; Rumberger \& Lim, 2008; Chakraborti, 2009).

Poverty is undoubtedly one of the established major barriers to education (Jayachandran, 2002; Hati \& Majumdar 2012; Hunt, 2008; Pramanik, 2015), particularly because education incurs a range of costs like school fees, uniforms, travel, and also the opportunity costs of sending a child to school (Tilak, 2002). Work involvement/child labor with or without payment of the poor children is another crucial factor. In India, girls are often involved in domestic and householdrelated duties, whereas boys are involved in agricultural labor either on their own or somebody else's farms. According to Dubey et al. (2018) the most important reason for boys to drop out of school is to take up jobs to supplement the family earning, whereas, for girls, it is the compulsion to participate in household work. Seasonal migration of parents 
along with their children harms children's education, because of the breaks or gaps in the study. However, parents permanently migrating to areas with better schooling facilities might increase the possibility of schooling for their children (Mitra, 2020). Ruralurban differences also impact the completion of education of the children.

Caste and other forms of social discrimination also play a major role in India. According to Balagopalan and Subrahmanian (2003) discrimination against underprivileged social groups, resulting in push out rather than drop out of children. Tribal children often remain OOS because of cultural hindrances among other reasons. When the language of instruction at school is not the children's native tongue, especially in the earlier years, can act as an exclusionary process (Gautam, 2003; Pankaj et al., 2018). Apart from the lack of proper disability-friendly infrastructure in schools, disabled children also face discrimination like considering disability a social taboo (Thurlow et al., 2002). This often keeps specially-abled children out of school. The education of parents particularly mothers' plays a major role in children's education. Educated parents realize the importance of education and thus are often more willing to send their children to schools (Jayachandran, 2002; Dostie \& Jayaraman, 2006; Hati \& Majumdar 2012; Pramanik, 2015). Female work participation also impacts children's education. In families where mothers go to work and there is no one else to support, often the elder children look after younger siblings and do domestic chores (Jayachandran, 2002). Orphanhood or death of parents negatively impacts schooling, particularly of poor children. The death of a mother increases domestic workload whereas the death of a single earning father is often linked to an increased likelihood of poverty and child labor (Hunt, 2008).

Among spatial factors, common economic influences like gross state domestic products and statelevel investment in education have often been found as significant aspects at the macro-level studies and village development variables at micro-level researches (Mitra, 2020). Other spatial factors are related to the accessibility of school-level infrastructure and resources e.g., rooms and boundary walls, availability of drinking water and toilets, etc. which varies significantly across the states and districts (Kumar et al., 2011). There have been studies to spatially map and identify the hot spot of supply-side variables (Saleh \& Balakrishnan, 2019) or map educational outcomes through indicators at the state level (Chatterjee \& Mishra, 2019).

Socio-political conflicts and emergencies in different parts of India also play a major role in children's education. Children caught up in conflict, politically fragile and emergencies often find difficulties remaining in school (Karam \& Somokanta, 2016; Pankaj et al., 2018). Bhatty et al. (2017) highlighted that the definition of "dropped out" children i.e. whose names are struck off the school records on account of continuous absence for a while, varies significantly from state to state. This impacts the estimation of "dropped out" children. For example, if a child is absent for seven days continuously without any information would qualify as a "dropped out" child in Karnataka, and his/her name would be struck off the rolls; but this will happen in Gujarat only if the child is continuously absent for 90 days. In Gujarat a child absents for 90 days over the whole year, but distributed in spurts (not continuous), would not be considered "dropped out" (Bhatty et al., 2017). This might include many seven days at a stretch! The conceptual framework has been summarized in Fig. 1.

\section{Data and methodology}

We used nationwide secondary data on 'Household Social Consumption: Education in India' as part of NSS's 75th round (July 2017-June 2018) survey. The survey covered the whole of the Indian Union except the villages in Andaman and Nicobar Islands due to difficulty to access. The survey covered 113,757 households (64,519 in rural and 49,238 in urban areas) and 513,366 persons (305,904 in rural and 207,462 in urban areas respectively) (GoI, 2019). However, for our study, only a subgroup of 117,115 children in the age group of 5-17 years was extracted from the unitlevel data. The justification for considering this age group is that this is the entire school-going age in India, and the national education policy 2020 of India talks about the universalization of school education for this entire age group. The sample size has been multiplied by the frequency weights (as per the formula provided in NSS) to estimate the total number of children in the country.

We followed a logistic regression analysis similar to Mitra (2020), which was used for exploring 


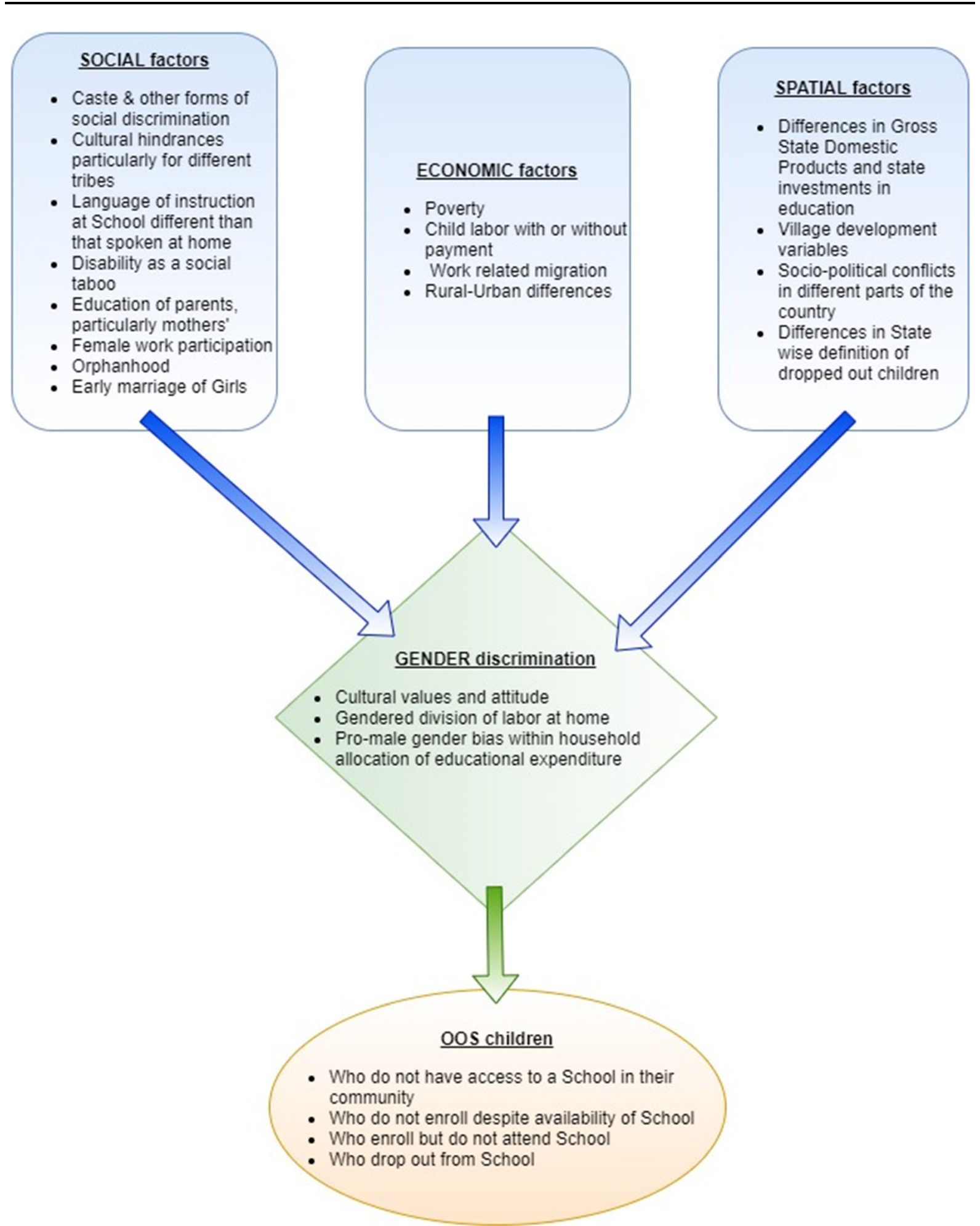

Fig. 1 Conceptual Framework of OOS Girls in India. Source: Conceptualized and prepared by the authors 
determinants of secondary education in India based on NSS $71^{\text {st }}$ round data. In the present study, the population or universe (children in the age bracket of 5-17 years) consist of three mutually exclusive groups - a) never attended school, b) attended school in the past but presently not attending or dropped out before completing secondary education, c) continuing education through either formal or informal mode. We defined the consolidation of the first two categories as OOS children, and estimated the following multivariate logistic regression:

$$
\begin{aligned}
\ln \left(\frac{P_{\text {oos }}}{1-P_{\text {oos }}}\right)= & \beta_{0}+\beta_{1}^{i} S E X^{i}+\beta_{2}^{j} E X P Q N T L^{j} \\
& +\beta_{3}^{k} S C T R^{k}+\beta_{4}^{l} S C G P^{l} \\
& +\beta_{5}^{m} R E L G N^{m}
\end{aligned}
$$

where, $P_{o o s}$ is the probability of being OOS of an individual child. It makes the dependent variable binary, i.e. it can take only two values, 1 for being OOS, and 0 for being in school. Among independent variables, our primary concern is gender dummySEX ${ }^{i}$, $i=1,2$, which takes two values, 1 for boys and 2 for girls respectively. Another independent variable of major concern is the economic class. Since NSS does not provide income data but the annual consumer expenditure instead, therefore we considered that as a proxy of household income. We generated the variable expenditure quintile as a proxy of economic class. Expenditure quintile dummyEXPQNTL ${ }^{j}, \quad j=$ $1,2,3,4,5$ take 5 values poorest (1), poorer (2), middle (3), richer (4), richest (5). Economic characteristic is also captured to some extent by rural-urban sectoral classification. Therefore, we incorporated a rural-urban dummySCTR ${ }^{k}, k=1,2$, where 1 and 2 imply rural and urban sectors respectively. Among social characteristics, we included social groups and religions. Social group dummySCGP $, l=1,2,3,4$ takes 4 values Scheduled Tribes (ST) (1), Scheduled Caste (SC) (2), Other Backward Class (OBC) (3), and General/Others (4). Religion dummyRELGN ${ }^{m}, m=1,2,3,4$, takes four values for Hinduism (1), Islam (2), Christianity (3), and Sikhism (4). We have considered only these four major religions since the population for other religions was negligible in the data set.

Our hypothesis for the independent variables are: a) likelihood of being OOS is higher for girls compared to boys, b) probability of being OOS decreases with more household income, c) likelihood of being OOS is lower in urban areas, due to availability of better infrastructure, educational facilities, and positive peer pressure or bandwagon effect, d) probability of being OOS is lower in general caste compared to other disadvantaged social groups due to lack of access and exposure to education historically, and e) compared to dominant religion i.e. Hinduism, the likelihood of being out of school is presumed to be higher in case of the minority religion Islam, and lower for Christianity due to historical reasons. To complement the findings of the logistic regression and capture the educational vulnerability overlapping with the socioeconomic disadvantage, we mapped the share of OOS children across socioeconomic classes. We constructed a treeshaped three-layer cross-tabulation with economic categories as first, social categories as second, and gender categories as the third layer respectively. The statistical analysis has been done using the software STATA13.

We calculated the existing probability of being OOS, for total children, and girl children, respectively. The ratio of the above two probabilities gave the relative probability of girls being OOS. To visualize the data spatially, NSS-region wide map was prepared. The NSS region is the spatial unit that has been demarcated based on NSS methodology, which divides 36 states and Union Territories of India into 88 NSS regions (Fig. 2). All the regions have been digitized using QGIS 3.8 software. The probability of being OOS has been spatially plotted as per these regions using the choropleth technique with five categories such as: very low, low, moderate, high, and very high, depicting the best to worst classification. Similarly, the relative probability of girl children being OOS has been categorized as lowest, lower, almost equal, higher, and highest. The vulnerable regions have been further analyzed based on statespecific socio-economic characteristics.

\section{Results and findings}

In India out of a total of 267 million children of 5 to 17 years of age group, almost 33 million children are OOS (Table 1). This implies that around $12.4 \%$ of children in the entire school-going age are OOS. The share of OOS girls $(13.3 \%)$ is higher than that of boys $(11.6 \%)$. 


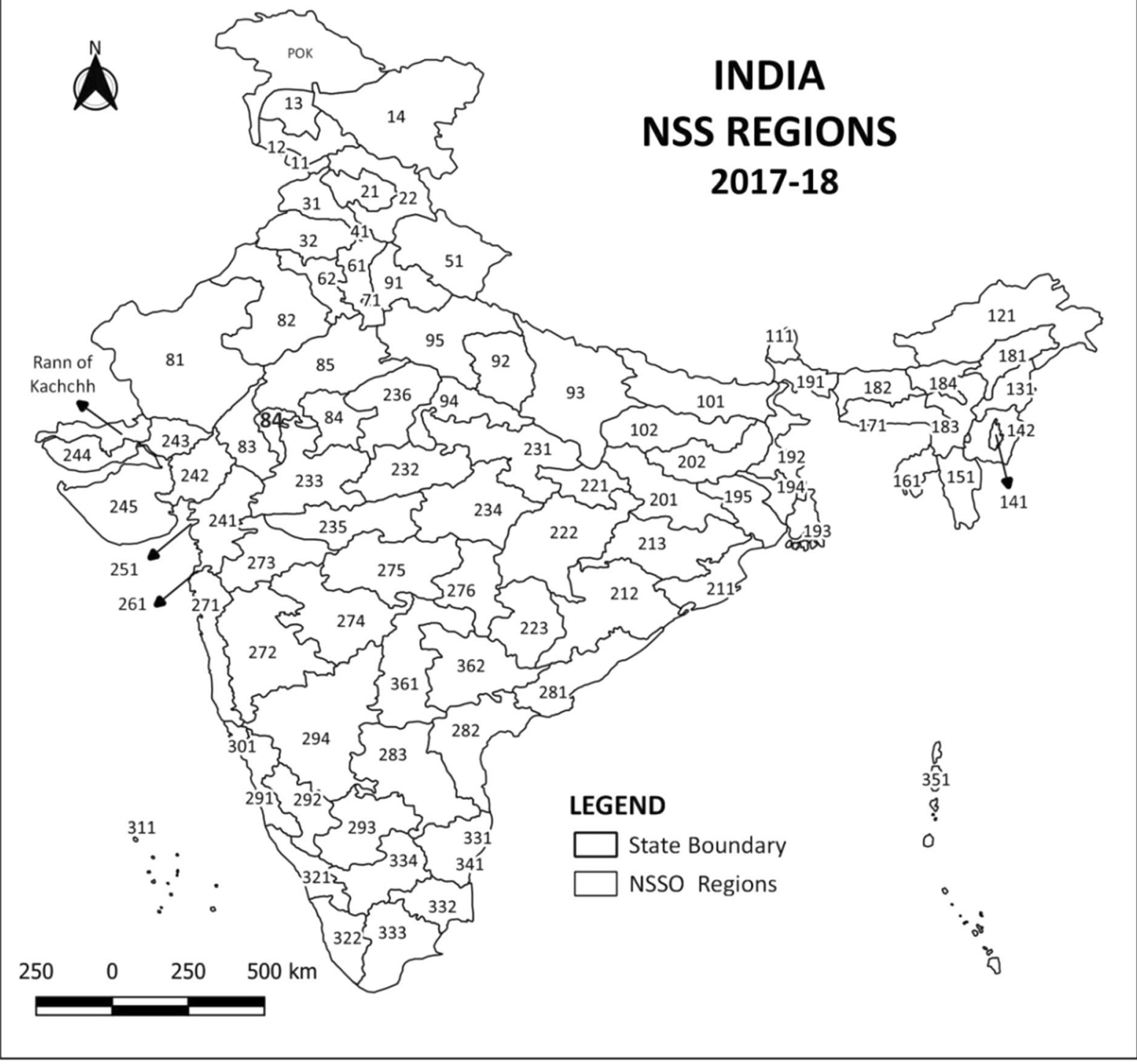

Fig. 2 NSS regions of India. Source: Prepared by the authors based on the shape-file downloaded from DIVA-GIS (https://www.divagis.org/)

Table 1 shows that the percentage is the lowest among the 6 to 13 years of age group. This highlights the importance of the present Right to Education (RTE) Act in the country, which covers the age group 6 to 14 years. The percentage of OOS children shoots up after this age group. Since the National Education Policy (2020) attempts to universalize the education of this entire age group, this sharp increase in the percentage of OOS children after the age of 14 is expected to mitigate in the future. However, the actual reality can only be seen in the future course of time.

Whether gender and other socio-economic backgrounds are significant determinants of OOS children in India?

The result of the multivariate logistic regression is presented in Table 2. As expected, we find that the likelihood of being OOS is on average at least $16 \%$ 
Table 1 Out of school children in India (5-17 years)

\begin{tabular}{|c|c|c|c|c|c|c|c|c|c|}
\hline \multirow[t]{2}{*}{ Level of education (age range) } & \multicolumn{3}{|c|}{$\begin{array}{l}\text { Numbers of total children (in } \\
\text { millions) }\end{array}$} & \multicolumn{3}{|c|}{$\begin{array}{l}\text { Numbers of OOS children } \\
\text { (in millions) }\end{array}$} & \multicolumn{3}{|c|}{$\begin{array}{l}\text { Percentage of OOS children in } \\
\text { total children }\end{array}$} \\
\hline & Boys & Girls & Total & Boys & Girls & Total & Boys & Girls & Total \\
\hline Pre-primary (5 years) & 9.6 & 8.0 & 17.6 & 3.5 & 2.9 & 6.4 & 36.7 & 36.1 & 36.4 \\
\hline Primary (6 to 10 years) & 58.4 & 46.6 & 105.0 & 2.5 & 2.8 & 5.2 & 4.2 & 5.9 & 5.0 \\
\hline Lower secondary (11 to 13 years) & 33.4 & 27.4 & 60.8 & 1.6 & 1.8 & 3.4 & 4.9 & 6.4 & 5.5 \\
\hline Upper secondary (14 to 17 years) & 46.2 & 37.6 & 83.7 & 9.5 & 8.5 & 18.0 & 20.6 & 22.5 & 21.5 \\
\hline Total ( 5 to 17 years) & 147.5 & 119.6 & 267.1 & 17.1 & 15.9 & 33.0 & 11.6 & 13.3 & 12.4 \\
\hline
\end{tabular}

Source: Authors' calculations based on NSS 75th round data (2017-18)

Table 2 Result of Logistic regression

\begin{tabular}{|c|c|c|c|c|c|}
\hline & 1 & 2 & 3 & 4 & 5 \\
\hline Constant & $0.13 * * *$ & $0.176 * * *$ & $0.18 * * *$ & $0.24 * * *$ & $0.26 * * *$ \\
\hline \multicolumn{6}{|c|}{ Gender dummy (reference category $=$ Boys) } \\
\hline Girls & 1. $16^{* * * *}$ & $1.18 * * *$ & $1.18 * * *$ & $1.17 * * *$ & $1.17 * * *$ \\
\hline \multicolumn{6}{|c|}{$\begin{array}{l}\text { Economic class dummies (reference } \\
\text { category }=\text { Poorest) }\end{array}$} \\
\hline Poorer & & $0.85^{* * *}$ & $0.86^{* * *}$ & $0.89 * * *$ & $0.87 * * *$ \\
\hline Middle & & $0.67 * * *$ & $0.72 * * *$ & $0.76 * * *$ & $0.75 * * *$ \\
\hline Richer & & $0.52 * * *$ & $0.59 * * *$ & $0.65 * * *$ & $0.65 * * *$ \\
\hline Richest & & $0.36 * * *$ & $0.45 * * *$ & $0.51 * * *$ & $0.53 * * *$ \\
\hline \multicolumn{6}{|c|}{ Sector dummy (reference category $=$ Rural) } \\
\hline Urban & & & $0.65 * * *$ & $0.68 * * *$ & $0.64 * * *$ \\
\hline \multicolumn{6}{|c|}{ Social category dummy (reference category $=\mathrm{ST}$ ) } \\
\hline $\mathrm{SC}$ & & & & $0.79 * * *$ & $0.76 * * *$ \\
\hline $\mathrm{OBC}$ & & & & $0.71 * * *$ & $0.53 * * *$ \\
\hline General/Others & & & & $0.50 * * *$ & $0.33 * * *$ \\
\hline \multicolumn{6}{|c|}{ Religion dummy (reference category = Hinduism) } \\
\hline Islam & & & & & $2.77 * * *$ \\
\hline Christianity & & & & & $0.46^{* * *}$ \\
\hline Sikhism & & & & & $0.56 * * *$ \\
\hline number of observations & $267,091,716$ & $267,091,716$ & $267,091,716$ & $267,091,716$ & $267,089,604$ \\
\hline LR chi2 & $165,553.42$ & $2,728,661.96$ & $3,415,035.33$ & $4,466,478.25$ & $9,098,007.36$ \\
\hline Prob $>$ chi 2 & 0.00 & 0.00 & 0.00 & 0.00 & 0.00 \\
\hline Pseudo R2 & 0.0008 & 0.0137 & 0.0171 & 0.0224 & 0.0456 \\
\hline
\end{tabular}

$* * *, * *, *$ indicate statistical significance of 1,5 , and $10 \%$ respectively

higher for girls compared to that of boys. This result is almost constant in all of our five econometric models. This result corroborates the argument established in the literature that the education of boys is often given priority over girls, and also the gendered division of labor within households which often forces girls to take on household duties and take care of younger siblings (Azam \& Kingdon, 2013; Bhatkal, 2012; Kaul, 2018). 
The hypothesis of poverty as a major barrier to education in India (Dubey et al., 2018; Hati \& Majumder, 2012; Sarkar, 2018; UNICEF, 2014) is also corroborated by our logistic regression analysis. Table 2 shows that the likelihood of children being OOS declines at every stage when we move from 'poorest' to the 'richest' quintile, consistently in all the four models. This is because education incurs a range of costs like school fees, uniforms, and travel. Moreover, there are opportunity costs attached to sending a child to school, particularly for poor parents. However, as we keep on adding other variables like a rural-urban dummy, social categories, and religion, the difference between odds ratios of different economic quintiles declines. This might be due to overlapping of issues, e.g., the children belonging to rural areas and backward social categories are also poor in most of the cases. Rural-urban differentiation comes out prominently in our regression analysis, with the probability of being OOS in urban areas being on an average $35 \%$ lower compared to rural areas. This is almost consistent in all three models. Regarding social categories, in comparison to STs, the probability of being OOS is lower in the case of SCs, OBCs, and particularly in the case of upper/general castes. This can be explained by cultural factors, as many tribes do not feel comfortable sending their children to schools with children from other communities, even today. Existing literature also specifies various reasons e.g. economic disadvantage, forms of social expectation, language difference in school and home, and discrimination against underprivileged social groups, which often push these children out of school (Balagopalan \& Subrahmanian, 2003; Gautam, 2003; Pankaj et al., 2018). We found that compared to Hindus, the likelihood of being OOS is higher among Muslim (Islam religion) children but lower among Christian and Sikh children.

The pseudo $\mathrm{R}^{2}$ value is McFadden, which is typically lower than Nagelkerke's pseudo $R^{2}$ for a given data set, and both are lower than $\mathrm{R}^{2}$ values for Ordinary Least Square (OLS) regressions. However, in our case, McFadden pseudo $\mathrm{R}^{2}$ is quite small. It is probably because we have looked into only the socioeconomic factors of the household and excluded the school-level factors, which play very important roles but are outside the scope of our study.
Who are the most vulnerable girls across different socio-economic classes?

Figure 3 presents the three-layer cross-tabulation with economic categories as first, social categories as second, and gender categories as the third layer respectively, showing the overlap of the educational vulnerability with the socioeconomic disadvantage. Our three-layer cross-tabulation reveals that poor Scheduled-Tribes girls are the most vulnerable group, with more than $21 \%$ share of OOS girls.

Figure 3 shows that the maximum share of OOS girls belongs to the Poorest and Poorer ST category (21.3 and $21.2 \%$ respectively) and lowest under the Richest General category (3.5\%). The five categories with the highest share of OOS girls are Poorest and Poorer ST, Poorest SC and OBC, and Poorer SC categories respectively. It implies that the girls from the poorest and poorer economic classes have the highest share of OOS girls.

Figure 3 provides further nuances. In ST and OBC categories gender differences play a major role and girls are more likely to be OOS. However, in poor SC households, both girls and boys do not go to school. Moreover, in the SC category, there is either no gender difference, or girls are less likely to be out of school. The general category shows a mixed trend. In the poorest and middle economic quintile, more boys are OOS, which might be due to the involvement of boys in economic activities, because the trend gets reversed in richer and richest categories. These finer nuances regarding the overlap of the educational vulnerability with the socioeconomic disadvantage are our contribution to the existing understanding of OOS children. However, for an in-depth understanding of the trend among various socioeconomic groups, there is a need and scope for further research with primary data and qualitative insights.

Where are the vulnerable regions in terms of the high probability of OOS girls located spatially?

We considered three indicators to measure and identify the vulnerable regions in terms of a high probability of OOS girls: a) probability of total children being OOS, b) probability of girl children being OOS, and c) relative probability (ratio of girls to total children) (Fig. 4). 


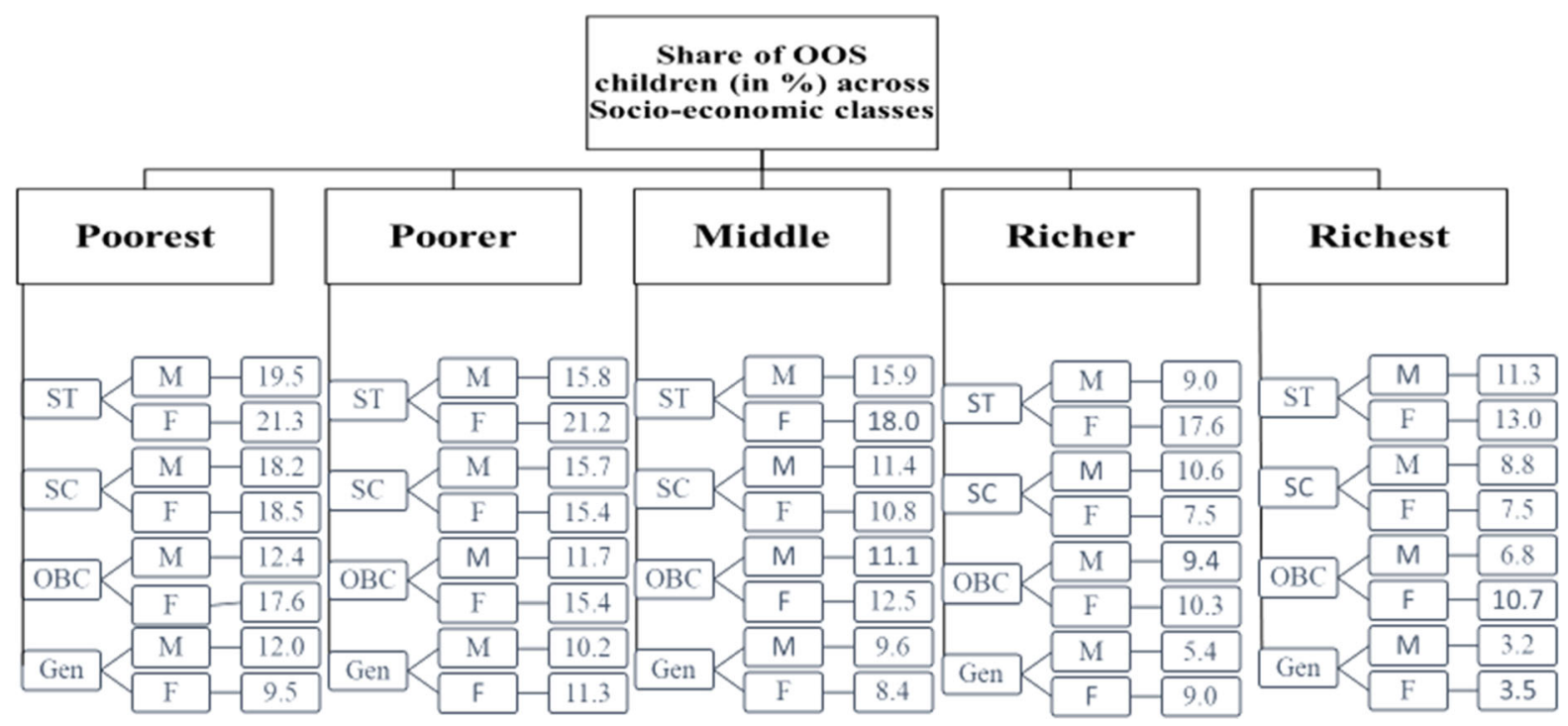

Fig. 3 Share of OOS children across socioeconomic classes. Source: Prepared by the authors

The probability of total children being OOS (Fig. 4a) shows that the most vulnerable region is the Northern Upper Ganga Plains of Uttar Pradesh state (region number: 91, probability value: 0.27 ) while the least vulnerable region is the Goa (region number: 301 , probability value: 0.00 ) and the national average is 0.12 (or $12 \%$ ).

Compared to 6 regions falling under the 'very high' category for total OOS children, there are 10 such NSS regions in the case of OOS girls (Fig. 4b). These regions belong to states like Rajasthan, western Madhya Pradesh, and northern Gujarat in western India, Uttar Pradesh in north India, and southern Chhattisgarh in central India. The probability of OOS girls is highest in the Northern Upper Ganga Plains region (region number: 91, probability value: 0.29) and lowest in the regions of Inland Eastern Karnataka, Goa, and northern Kerala (region number: 292, 301, 321 , respectively, probability value: 0.00 ), while the national average is $0.13(13 \%)$.

Relative probability, which is the ratio of OOS girl children to total OOS children, represents girls' vulnerability. Compared to the relative probability of 1.07 at the national level, it has been found that at the regional scale it varies from 0.00 in Goa to 1.95 in Coasts \& Ghats of Karnataka (Fig. 4c). Figure 4c depicts that across the country there are many regions with a comparatively lower probability of total OOS children but high relative probability (more than 1.16 ).
Combining the spatial distribution of 'high' to 'very high' probability of OOS girls and 'highest' relative probability, we conclude Rajasthan, Uttar Pradesh (particularly western part), Madhya Pradesh, Chhattisgarh (particularly southern part), and Gujarat to be vulnerable states in terms of a higher probability of girls being OOS.

To have a better understanding of the factors behind the reasons for the higher vulnerability of OOS girls, the socio-economic profile of OOS girls has also been mapped at the state level. The state-level spatial distributions of the economic profile, rural-urban distribution, social and religious compositions of OOS girls have been shown in Fig. 5.

Figure 5a depicts that girls from the poorest backgrounds are majorly out of school. This trend is prominent in the states of Rajasthan, Madhya Pradesh, and Chhattisgarh. Interestingly the majority of the OOS girls belong to the middle-income quintile in Gujarat and the richest income quintile in Uttar Pradesh. Apart from a few states, most of the states are agriculture-based and thus dominated by the rural sector (Fig. 5b). Therefore, one cannot draw the spatial correlation with the probability of OOS. Apart from Uttar Pradesh, for all the other vulnerable states majority of OOS girls belong to rural areas. Coming to social composition, in all the vulnerable states majority of OOS girls belong to OBC. Moreover, in Madhya Pradesh and Chhattisgarh, a major share of OOS girls 

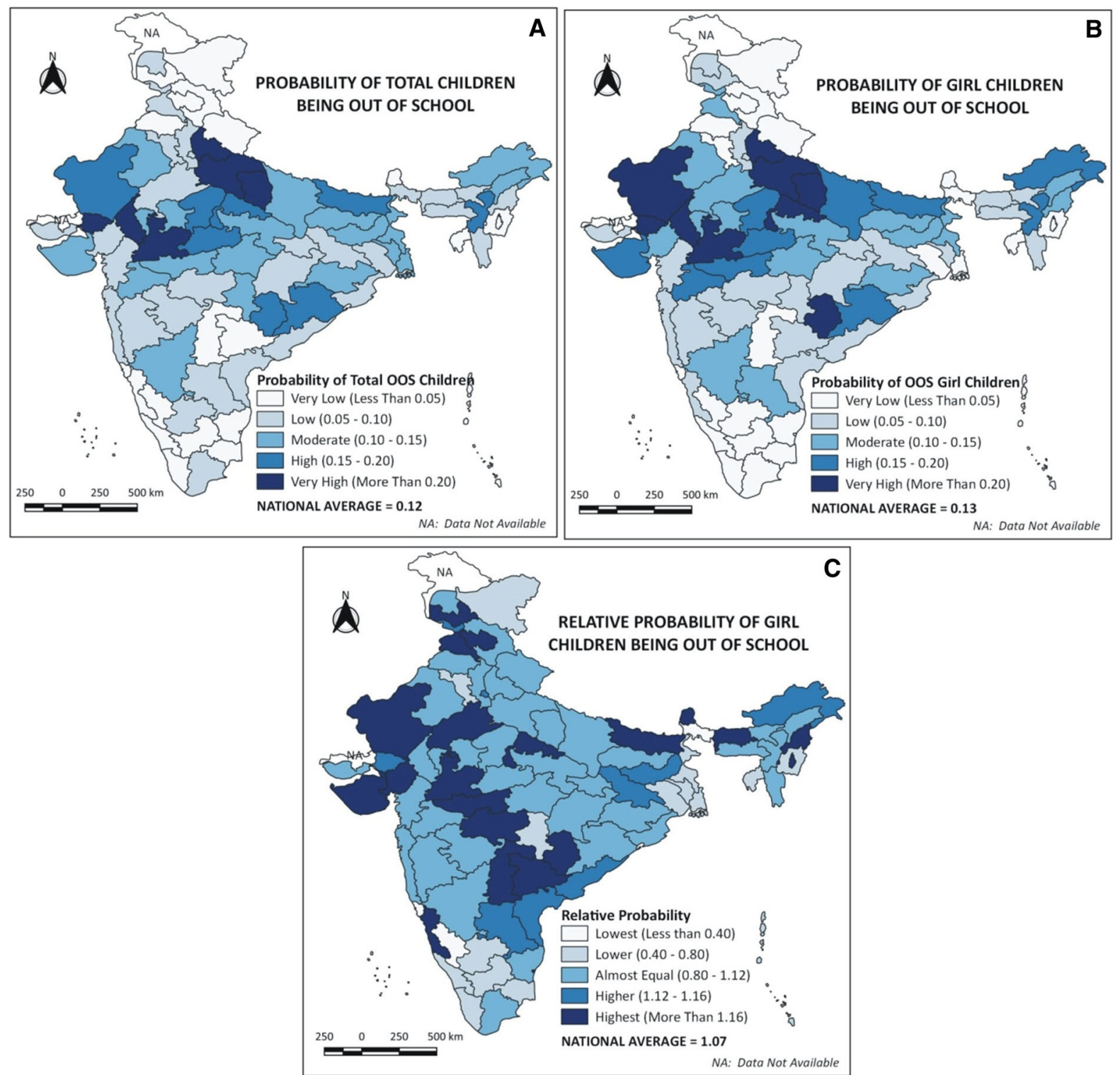

Fig. 4 Vulnerable regions in India in terms of a high probability of OOS girls. Source: Prepared by the authors

belongs to ST (Fig. 5c). It is difficult to establish a spatial relationship with any particular religion because almost all vulnerable regions are majorly dominated by Hindu (Fig. 5d).

\section{Discussions}

The general understanding about the OOS children in India has been established in the literature (Dubey et al., 2018; Sarkar, 2018; UNICEF, 2014) - they come from socioeconomically disadvantaged backgrounds and are often girls. This paper re-establishes the fact with logistic regression analysis, using recent country-level largest sample data. The three-layer cross-tabulation diagram shows the inter-linkages of socioeconomic factors and gender explicitly and adds further nuances to the existing debate. Spatial mapping of educational infrastructure and access has been reported in the existing literature (Chatterjee \& Mishra, 2019; Kumar et al., 2011; Saleh \& Balakrishnan, 2019), but that of OOS girls from different 

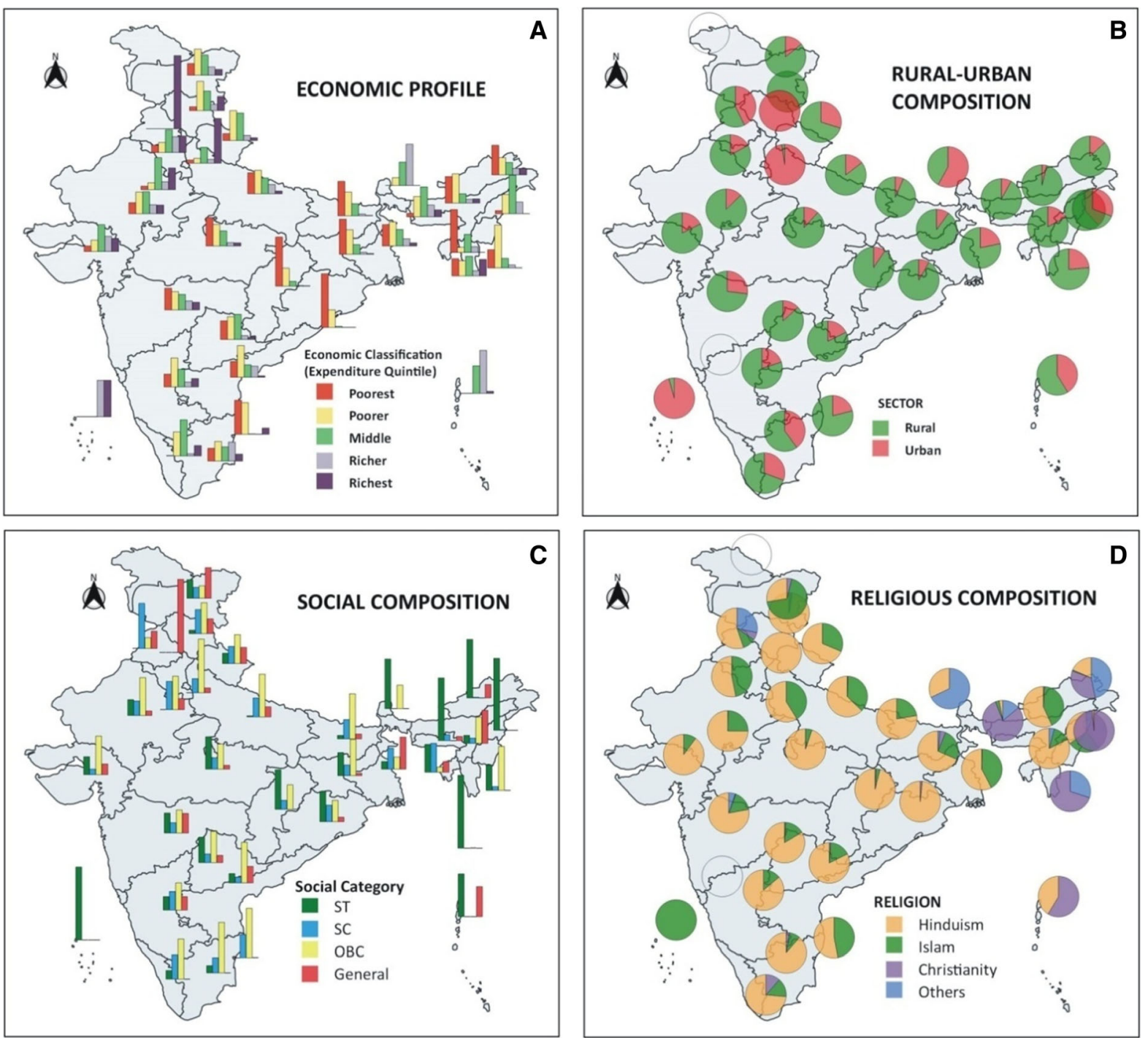

Fig. 5 State-wise socio-economic profiling of the OOS Girls. Source: Prepared by the authors

socioeconomic backgrounds is another value addition of this article.

In the contemporary context, when the country is recovering from the second phase of the COVID-19 pandemic and preparing to safeguard from the third wave, any discussion on education is incomplete without touching upon the impact of the pandemic and the future implications. According to UNESCO (2021), COVID-19 has pushed inequalities in education by disproportionately affecting adolescent girls. Historically also it has been found that in times of severe economic downturn, civil strife, or epidemic disease, existing gender inequality in education has always got exacerbated (Burde et al., 2017; Chesterfield et al., 2001; Malala Fund, 2020; UNESCO, 2020). NSS 75th round data can be treated as the largest pan India level sample of educational data of the pre-COVID-19 times in the country. Thus, in this section, we discuss some of the findings in the context of the present pandemic situation and its future implications.

We found the likelihood of OOS children in rural areas to be almost $35 \%$ higher compared to urban areas. As an immediate outcome of the pandemicinduced lockdown process in India, a large number of households have been pushed to the rural areas and 
subsistence living. It implies that children from those families are probably at higher risk of being OOS. This might increase the already existing rural-urban gap of OOS children.

According to the existing literature, any form of crisis finally gets translated into an economic crisis, which forces some families to struggle for surviving and thus prioritize children's education less (Stromquist, 2001; World Bank, 2020). In India, the COVID19 crisis impacted household incomes significantly (Business Keelery, 2020; Sumner et al., 2020; Today, 2021). Logistic regression results show that the likelihood of OOS children is consistently higher for every stage of income quintile from 'richest' to the 'poorest'. It implies that with the predicted decline in family income, the possibilities of OOS girls will increase for sure. At the same time, there might also be a shift of girls from private to government schools.

According to the NSS data, the share of girls going to government school varies with the economic quintile. Data shows that $67,64,58,46$, and $32 \%$ of girls of Poorest, Poorer, Middle, Richer, and Richest quintile respectively go to government schools. A major reason is that the average annual expenditure of government schools is noticeably lower than that of private schools (Table 3). The two-way ANOVA model on the mean expenditure on education data shows that in the case of both government and private schools there are not only significant variations among the economic groups (column) for any social category but also among the social categories (rows) within any particular economic class (Table 3). It implies that as households move from upper to lower economic quintiles, the expenditure on education varies significantly. Moreover, there are variations among social categories also.

Although the share of girls being OOS is lower among middle, richer, and richest quintiles (Fig. 3), many girls from these categories go to private schools. The average annual expenditure on education is more than 5 to 6 times in private schools compared to government schools (Table 3). Therefore, with a reduction in household income, many girls from upper quintiles might shift to government schools. Moreover, the ANOVA test suggests that the pattern of withdrawal from private schools might not be uniform across different social classes. Therefore, strengthening the public education system is an urgent need of the hour so that some girls do not become further OOS due to a crowding-out effect.

\section{Conclusions and recommendations}

NSS data provides information of three mutually exclusive groups-(a) never attended school, (b) attended school in the past but presently not attending or dropped out before completing secondary education, (c) continuing education through either formal or informal mode. We defined the consolidation of the first two categories as OOS children. As a part of UNICEF's global initiative on OOS children, children attending school but at the greatest risk of dropping out have also been taken into account. In that context, we suggest that NSS data should also try to capture information of children who are at risk of being OOS. This can be done by including variable(s) such as how many days he/she attended the school in the last academic year. Also, in the face of COVID-19 related temporary school closure which increased the probability of children being OOS, variables like access to online education, support received from parents/ schools/government/NGOs during school closure will be useful.

India being a large country there are socioeconomic and spatial disparities regarding OOS girls. We found that around $12.4 \%$ of children in the entire schoolgoing age (5 to 17 years) are OOS. The share of OOS girls $(13.3 \%)$ is higher than that of boys (11.6\%). The multivariate logistic regression analysis shows that gender and socioeconomic factors are significant determinants. Thus, our findings corroborate the general understanding about the OOS children in India - they come from socioeconomically backward backgrounds and are often girls. Moreover, the threelayer cross-tabulation diagram shows the inter-linkages of socioeconomic factors and gender explicitly and adds further nuances to the existing debate. In ST and $\mathrm{OBC}$ categories girls are more likely to be OOS. However, in the SC category, there is either no gender difference, or girls are less likely to be out of school. The general category shows a mixed trend. In the poorest and middle economic quintile, more boys are OOS, but the trend gets reversed in richer and richest categories. Further research is required for an understanding of these differences. Spatial mapping of educational infrastructure and access in India has been 
Table 3 Annual expenditure on education (government vis-à-vis private school)

\begin{tabular}{|c|c|c|c|c|c|c|c|c|c|c|c|c|c|c|}
\hline & \multicolumn{2}{|c|}{ Poorest } & \multicolumn{4}{|c|}{ Poorer } & \multicolumn{3}{|c|}{ Middle } & \multicolumn{2}{|l|}{ Richer } & \multicolumn{2}{|l|}{ Richest } & $\begin{array}{l}\text { ANOVA } \\
\text { (Columns) (Girls) }\end{array}$ \\
\hline \multicolumn{15}{|c|}{ Average annual expenditure on education of government school children (5-17 years) (in INR\#) } \\
\hline Group & Boys & Girls & Boy & & Gir & & Boy & ys & & Boys & Girls & Boys & Girls & \multirow{5}{*}{$\begin{array}{l}p=0.001 \\
(\mathrm{~F}=9.395, \mathrm{~F} \\
\quad \text { crit }=3.259)\end{array}$} \\
\hline ST & 1353 & 1337 & 166 & & 164 & & 1878 & & & 2131 & 2482 & 4201 & 4220 & \\
\hline $\mathrm{SC}$ & 1667 & 1676 & 215 & & 205 & & $259^{7}$ & & & 2889 & 2722 & 3298 & 2763 & \\
\hline OBC & 2059 & 1792 & 195 & & 187 & & 235 & & & 2875 & 2485 & 4168 & 3681 & \\
\hline General/Others & 3640 & 2541 & 318 & & 319 & & 445 & & & 5197 & 4849 & 8030 & 7510 & \\
\hline $\begin{array}{c}\text { ANOVA } \\
\text { (Rows) } \\
\text { (Girls) }\end{array}$ & \multicolumn{14}{|c|}{$p=0.001(\mathrm{~F}=10.658, \mathrm{~F}$ crit $=3.490)$} \\
\hline \multicolumn{15}{|c|}{ Average annual expenditure on education of private school children (5-17 years) (in INR) } \\
\hline Group & Boys & $\mathrm{Gi}$ & & Bo & & Gir & & Boys & Girls & Boys & Girls & Boys & Girls & \multirow{5}{*}{$\begin{array}{l}p=0.000 \\
(\mathrm{~F}=17.989, \mathrm{~F} \\
\quad \text { crit }=3.259)\end{array}$} \\
\hline ST & 8771 & 76 & & 10 , & 712 & 914 & & 12,673 & 11,120 & 12,748 & 13,095 & 19,187 & 15,240 & \\
\hline $\mathrm{SC}$ & 7492 & 75 & & 84 & & 787 & & 11,575 & 11,562 & 15,184 & 12,865 & 25,526 & 21,132 & \\
\hline $\mathrm{OBC}$ & 9834 & 84 & & 98 & & 912 & & 12,802 & 11,273 & 16,506 & 14,342 & 24,692 & 22,256 & \\
\hline General/Others & 12,591 & & 936 & 12 , & 953 & 10 , & 598 & 14,999 & 12,747 & 20,421 & 19,814 & 36,024 & 32,254 & \\
\hline $\begin{array}{c}\text { ANOVA } \\
\text { (Rows) } \\
\text { (Girls) }\end{array}$ & \multicolumn{14}{|c|}{$p=0.021(\mathrm{~F}=4.771, \mathrm{~F}$ crit $=3.490)$} \\
\hline
\end{tabular}

${ }^{\#}$ The exchange rate is $1 \mathrm{USD}=74.14 \mathrm{INR}$ as on 20.06 .21

Source: Prepared by authors, based on unit data of NSS 75th round (2017-18)

there in the existing literature, but that of OOS girls from different socioeconomic backgrounds is another value addition of this article. The spatial distribution shows a very high probability of being OOS to be located in the northern and western parts of the country. On the other hand, most of the southern Indian states show 'low' or 'very low' probability. Therefore, within India, there is the scope of learning from the southern states and replicating some of the best practices in the northern and western states. Our study suggests further research in this kind of spatial aspect. We also found that across the country there are many regions with a comparatively lower probability of total OOS children but high relative probability i.e. the ratio of OOS girls to total OOS children. Further research at the micro-level will be useful to find out specific reasons behind this. We found that majority of the OOS girls belong to the middle-income quintile in Gujarat and the richest income quintile in Uttar Pradesh. This finding is in sharp contradiction to the rest of the country, which calls for further research to explore the reasons behind this aberration of trend.
In the present context of the COVID-19 pandemic, with a decline in family income and an increase in reverse migration, numbers of OOS girls might increase. At the same time, there might also be a shift of girls from private to government schools as established by our ANOVA test. Therefore, strengthening the public education system is essential so that some girls do not become further OOS. However, there might be serious limitations to interpolating our findings based on a data set collected much before the pandemic situation. We agree that the actual postpandemic situation might be much more serious given the complex interplay of various issues related to girls' education in India. Further research on comparative analysis of this work and similar analysis using the next round of NSS survey will be helpful to examine the impact of COVID-19 on OOS girls.

The other limitation of this study is that the supply side issues are beyond the scope, we overlooked two crucial factors, namely distance to school and school infrastructure. Distance of school is important in the face of school closure/merger policies of the present government, and infrastructure becomes equally 
crucial in the context of post-COVID-19 school reopening. This calls for future research in these two areas. Another limitation of the study is not to include an important determinant of OOS girls, namely early marriage. During our own fieldwork experiences, we have realized that it is really difficult to capture data on early marriages, because both parents and married girls overstate their age, as they know the minimum age of marriage is legally 18 years. Further research on whether school dropouts lead to early marriage or early marriage leads to OOS girls will be interesting, particularly in the present context when the country is debating whether the minimum age of marriage should be extended to 21 years or not. Despite the abovementioned limitations, this first of its kind holistic study on socioeconomic and spatial disparities of OOS girls in India is the major strength of the paper which indicates many further scopes of research.

Our study indicates that to achieve SDG 4 and SDG 5 by 2030, serious attention should be given to bringing back the huge number of OOS children, particularly girls, to the school premises. Based on our findings we argue for localized solutions for girls of diverse socioeconomic backgrounds in different regions, and strengthening of the public education system.

Acknowledgements Authors are grateful to Dr. Sabir Ahamed, Pratichi Trust, Kolkata, and Dr. Zakaria Siddiqui, Gulati Institute of Finance and Taxation, Thiruvananthapuram, India, for providing help in accessing unit level NSS (2017-18) data. We appreciate comments from anonymous reviewers that led to significant improvements in the paper.

Funding This research received no external funding.

Availability of data and material The datasets generated during and/or analyzed during the current study are available from the corresponding author on reasonable request.

Code availability Not applicable.

\section{Declarations}

Conflict of interest We, the authors of this manuscript, declare that there is no competition of interest with any individual, institutes, or agencies.

Ethics approval Not applicable.

Consent to participate Not applicable.
Consent for publication We accept the terms of this journal for publication.

Data source NSSO data of 75th round (2017-18). Ministry of Statistics \& Programme Implementation, Government of India.

\section{References}

Abu-Ghaida, D., \& Klasen, S. (2004). The costs of missing the millennium development goal on gender equity. World Development, 32(7), 1075-1107.

Azam, M., \& Kingdon, G. G. (2013). Are girls the fairer sex in India? Revisiting intra-household allocation of education expenditure. World Development, 42, 143-164.

Balagopalan, S., \& Subrahmanian, R. (2003). Dalit and Adivasi children in schools: Some preliminary research themes and findings. IDS Bulletin, 34(1), 43-54.

Bertini, C., \& Ceretti, A. (2020). Women and girls as change agents: the global mandate for girls' education. Retrieved from: https://www.thechicagocouncil.org/sites/default/ files/womengirlschangeagents_report.pdf

Bhatkal, T. (2012). Gender bias in the allocation of education expenditure: Evidence from Andhra Pradesh, India. Unpublished master's thesis, University of Oxford, UK. Retrieved from: http://r4d.dfid.gov.uk/PDF/Outputs/ Younglives/gender-bias-in-the-allocation-ofeducationexpenditure.pdf.

Bhatty, K., Saraf, R., \& Gupta, V. (2017). Out-of-school children. Economic and Political Weekly, 52(49).

Birdsall, N., Ross, D., Sabot, R., De Haen, H., \& Sathar, Z. A. (1993). Underinvestment in education: How much growth has Pakistan foregone? The Pakistan Development Review, 32(4), 453-499.

Burde, D., Kapit, A., Wahl, R. L., Guven, O., \& Skarpeteig, M. I. (2017). Education in emergencies: A review of theory and research. Review of Educational Research, 87(3), 619-658.

Business Today (2021). 10 million lost jobs in Covid 2nd wave, 97\% households' income declined: CMIE. (1st June 2021). Retrieved from:https://www.businesstoday.in/current/ economy-politics/income-of-97-households-declinedsince-covid-19-pandemic-began-cmie/story/440498.html

Chakrabarti, A. (2009). Determinants of participation in higher education and choice of disciplines: Evidence from urban and rural Indian youth. South Asia Economic Journal, 10(2), 371-402.

Chatterjee, S., \& Mishra, U. S. (2019). Educational development and disparities in India: district-level analyses. In The demographic and development divide in India (pp. 259-328). Springer, Singapore.

Chesterfield, R., Enge, K. I., \& Martinez-Enge, P. (2001).Girls' education and crises. United States Agency for International Development.

Dostie, B., \& Jayaraman, R. (2006). Determinants of school enrolment in Indian villages. Economic Development and Cultural Change, 54(2), 405-421.

Dubey, M., Pankaj, A., \& Mitra, S. (2018). Still too many children out of school. The Hindu, 4, 6-18. 
Gautam, V. (2003). Education of tribal children in India and the issue of Medium of Instruction: A Janshala experience. UN/Government Janshala Programme. New Delhi.

GoI (2019). Key indicators of household social consumption on education in india. ministry of statistics \& programme implementation, National Statistical Office, Government of India

Hati, K. K., \& Majumder, R. (2012). Proximate determinants of school dropout: A study on Rural West Bengal.

Hill, M. A., \& King, E. (1995). Women's education and economic well-being. Feminist Economics, 1(2), 21-46.

Hunt, F. (2008). Dropping out from school: A cross country review of literature. Consortium for Research on Educational Access, Transitions, and Equity (CREATE) Research Monograph No 16

Jayachandran, U. (2002). Socio-economic determinants of school attendance in India (No. 103, Centre for Development Economics).

Jensen, R. (2012). Do labor market opportunities affect young women's work and family decisions? Experimental evidence from India. The Quarterly Journal of Economics, 127(2), 753-792.

Karam, S. D., \& Somokanta, T. (2016). Education in a Conflictridden State, Manipur. Economic and Political Weekly, 51(47), 53.

Kaul, T. (2018). Intra-household allocation of educational expenses: Gender discrimination and investing in the future. World Development, 104, 336-343.

Keelery, S. (2020). COVID-19 impact on household income in India 2020.Statista. Retrieved from: https://www.statista. com/statistics/1111510/india-coronavirus-impact-onhousehold-income/

Kelly, O., Krishna, A., \& Bhabha, J. (2016). Private schooling and gender justice: An empirical snapshot from Rajasthan, India's largest state. International Journal of Educational Development, 46, 175-187.

Kim, J. (2016). Female education and its impact on fertility. IZA World of Labor.

Kingdon, G. G. (2002). The gender gap in educational attainment in India: How much can be explained? Journal of Development Studies, 39(2), 25-53.

Kumar, V., Kumar, N., \& Narula, S. (2011). Mapping of elementary educational infrastructure in India: A state and district level analysis. IAMURE International Journal of Multidisciplinary Research, 1(1), 1-1.

Lancaster, G., Maitra, P., \& Ray, R. (2008). Household expenditure patterns and gender bias: Evidence from selected Indian states. Oxford Development Studies, 36(2), 133-157.

Malala Fund 2020. Girls' Education and COVID-19: What past shocks can teach us about mitigating the impact of Pandemic. Retrieved from: https://malala.org/newsroom/ archive/malala-fund-releases-report-girls-educationcovid-19

Marphatia, A. A., Reid, A. M., \& Yajnik, C. S. (2019). Developmental origins of secondary school dropout in rural India and its differential consequences by sex: A biosocial lifecourse analysis. International Journal of Educational Development, 66, 8-23.

Mitra, S. (2020). Socio-Economic Determinants of Secondary Education in India. In Tilak, J.B.G (Ed.) Universal
Secondary Education in India (pp. 245-262). Springer, Singapore.

Mohanty, I., \& Rammohan, A. (2015). Child schooling in India: the role of gender. Indian growth and development review.

Munshi, K., \& Rosenzweig, M. (2006). Traditional institutions meet the modern world: Caste, gender, and schooling choice in a globalizing economy. American Economic Review, 96(4), 1225-1252.

Pankaj, A., Mitra, S., \& Borah, A. (2018). Status of and Barriers to School Education in Chhattisgarh. Project Report published by Council for Social Development. ISBN 978-935346-516-2

Pankaj, A., \& Mitra, S. (2019). Out of School Children in India: A Baseline Survey of Patna (Bihar) and Hamirpur (Uttar Pradesh) Districts. Project Report published by Council for Social Development. ISBN:978-81-940733-3-8

Pramanik, S. (2015). The effect of family characteristics on higher education attendance in India: A multivariate logit approach. Higher Education for the Future, 2(1), 49-70.

Rumberger, R. W., \& Lim, S. A. (2008). Why students drop out of school: A review of 25 years of research. California Dropout Research Project, 15, 1-3.

Sahoo, S. (2017). Intra-household gender disparity in school choice: Evidence from private schooling in India. The Journal of Development Studies, 53(10), 1714-1730.

Saleh, I. A., \& Balakrishnan, P. (2019). GIS based hotspot and cold-spot analysis for primary education in India. Indian Journal of Science and Technology, 12, 45.

Sarkar, A. (2018). Out of the school children and their participation in economic and other domestic activities in India: A study based on recent NSS data. Journal of Social and Economic Development, 20(1), 75-109.

Schultz, T. P. (2002). Why governments should invest more to educate girls. World Development, 30(2), 207-225.

Sperling, G. B., Winthrop, R., \& Kwauk, C. (2016). What works in girls' education: Evidence for the world's best investment. Brookings Institution Press.

SRI-IMRB Report (2014). National Sample Survey of Estimation of Out-of-School Children in the Age 6-13 in India. Social and Rural Research Institute and IMRB International

Stromquist, N. P. (2001). What poverty does to girls' education: The intersection of class, gender, and policy in Latin America. Compare A Journal of Comparative and International Education, 31(1), 39-56.

Summers, L. H. (1992). Investing in all the people (The Quaid-iAzam Lecture). The Pakistan Development Review, 31(4I), 367-404.

Sumner, A., Hoy, C., \& Ortiz-Juarez, E. (2020). Estimates of the Impact of COVID-19 on Global Poverty. UNU-WIDER, April, 800-9.

Thurlow, M. L., Sinclair, M. F., \& Johnson, D. R. (2002). Students with disabilities who drop out of school: Implications for policy and practice. issue brief: Examining current challenges in secondary education and transition.

Tilak, J. B. (2002). Determinants of household expenditure on education in rural India (No. 88). New Delhi: National Council of Applied Economic Research.

UIS (2019). New Methodology Shows that 258 Million Children, Adolescents and Youth Are Out of School. Fact Sheet no. 56. (September 2019). UIS/2019/ED/FS/56 
UNESCO (2020). Covid-19 school closures around the world will hit girls' hardest. Retrieved from: https://en.unesco. org/news/covid-19-school-closures-around-world-willhit-girls-hardest

UNESCO (2021). \# Her Education Our Future: keeping girls in the picture during and after the COVID-19 crisis; the latest facts on gender equality in education. Global Education Monitoring Report. Programme and meeting document, 2021. Retrieved from: https://unesdoc.unesco.org/ark:/ 48223/pf0000375707

UNICEF (2014). South Asia regional study covering Bangladesh, India, Pakistan, and Sri Lanka. Global Initiative on Out-of-School Children. UNESCO Institute for Statistics, Kathmandu, Nepal.
White, G., Ruther, M., \& Kahn, J. (2016). Educational inequality in India: An analysis of gender differences in reading and mathematics. University of Maryland College Park.

World Bank (2020). The covid-19 pandemic: Shocks to education and policy responses. World Bank Group Publishing.

Publisher's Note Springer Nature remains neutral with regard to jurisdictional claims in published maps and institutional affiliations. 